\title{
The study of the correlations between handgrip strength and some anthropometric characteristics of upper extremity of elite and sub- elite olympic style weightlifting athletes
}

Kenan Erdağ ${ }^{\mathrm{ABCDE}}$

Necmettin Erbakan University, Konya, Turkey

Authors' Contribution: A - Study design; B - Data collection; C - Statistical analysis; D - Manuscript Preparation; E- Funds Collection.

\begin{abstract}
Purpose: $\quad$ Handgrip strength is widely used as a functionality parameter of the upper extremity and general health. The measurement of handgrip strength by dynamometry is a low cost, noninvasive method of simple applicability. The study aims to find out handgrip strength and its correlation with some anthropometric characteristics of the upper extremity and weightlifting performance of elite (international medalists) and sub-elite (national medalists) Olympic style weightlifting athletes.

Material: $\quad$ We obtained anthropometric measurements of upper extremity of elite athletes ( $n=25$ male, $n=20$ female) and sub-elite athletes ( $n=25$ male, $n=29$ female) in the study. Dominant and non-dominant handgrip strength measurements of the groups were obtained by a Jamar dynamometer, according to the recommendations of the American Association of Hand Therapists.

Results: $\quad$ No statistically significant difference was observed in non-dominant handgrip strength of male elite and subelite weightlifting athletes. Similarly, no significant difference was observed in between some anthropometric characteristics of upper extremity and dominant and non-dominant handgrip strength of female elite and sub-elite weightlifting athletes. We didn't find any asymmetry between dominant and non-dominant handgrip strength of study groups. We found a significant correlation between dominant and non-dominant handgrip strength of male and female elite athletes and their height, body weight, BMI and weightlifting performance.
\end{abstract}

Conclusions: Consequently, we might explain that adding special exercises into the general trainings of athletes to develop handgrip strength might contribute to the weightlifting performance of the athletes.

Keywords: olympic-style weightlifting, elite athletes, handgrip strength, anthropometry.

\section{Introduction}

Muscular contraction is defined as changes in the length of the muscle during contraction and it can be classified into isotonic or isometric [1]. Though isometric contractions do not cause a change in muscle length, they cause fluctuating tension and energy rates. These contractions occur in static positions, during which the angle of the joint is stable [2]. Isometric contractions are needed in physical activities of daily life and of sporting events. These activities and events require high activity levels of the flexor muscles of forearms and hands [1]. As one of the functions of the muscles in hands and forearms, handgrip strength (HGS) is an isometric strength [3]. To assess HGS, the most widespread method is to use a handheld dynamometer. The measurement has frequently been used as an indicator of overall physical strength and muscle performance, individual nutritional status and health, by a simple and non-invasive evaluation [1]. HGS has some physiological variables which are affected by a number of factors including age, body, height, BMI and body weight $[4,5,6]$. Strong correlations between HGS and some anthropometric characteristics of the upper extremity were reported in various studies in literature [7-11]. Anthropometric and physiological characteristics of groups with different sporting events with different o Kenan Erdağı, 2020

doi:10.15561/20755279.2020.0103 levels were extensively examined in different studies. N1kooie et al. [12] stated that HGS of male senior and junior wrestlers was bigger than HGS of less successful wrestlers. In a study to determine physical performance and motor coordination of elite and sub-elite female volleyball athletes, it was found that no statistically significant difference exists in HGS values of elite and sub-elite female volleyball athletes [13]. Pizzigalli et al. [10] reported that dominant and non-dominant HGS differences observed in female senior basketball athletes might be owing to overall conditions and training years of top level category athletes. Dominant and non-dominant HGS differences observed in tennis athletes might be caused by asymmetrical trainings in tennis [8]. In studies to find out the correlation between HGS and performance, it was reported that HGS and performance of the athletes are positively related $[14,15]$.

In literature, there are various studies assessing HGS values in different sports of elite and non-elite $[11,16$, 17], elite and sub-elite athletes [18] and individuals doing sports and individuals doing no sports [8]. We found different studies on the evaluation of HGS of male Olympic style weightlifting athletes $[19,20]$. However, there are limited studies regarding HGS values and the correlation between HGS and anthropometric characteristics of upper extremity [15]. Surprisingly, no studies exist in literature 
regarding female athletes in Olympic style weightlifting.

In the study, we aimed to find out HGS and its correlation with some anthropometric characteristics of the upper extremity and weightlifting performance (snatch, clean and jerk) of the elite international medalist athletes participated in international Olympic style weightlifting championships and sub-elite national medalist athletes participated in national championships.

\section{Materials and methods}

\section{Participants}

The study was performed in August during a national Oympic style weightlifting training camp (Ankara, Kocaeli, Kayseri in Türkiye) held before the World and European Championships in 2019. All participants (male and female athletes) completed a personal information form including their age, weight category, training background, and medals obtained during the 2018-2019 World Weightlifting Championships, European Weightlifting Championships or International tournament. In our study, athletes awarded a medal in international Olympic style weightlifting championships were categorized as elite weightlifting athletes (EWL), male (MWL, $n=25)$ and female (FWL, $n=20$ ). Types of medals (gold, silver and bronze) awarded by MWL and FWL in EWL were noted. Athletes awarded a medal in national Olympic style weightlifting championship were categorized as sub-elite weightlifting athletes (sub-EWL), male (MWL, $\mathrm{n}=25)$ and female $(\mathrm{FWL}, \mathrm{n}=20)$. All athletes in sub-EWL group were the ones that participated in national weightlifting teams in 2019. Each participant of the study was asked to fill in a questionnaire about former and current competitive performances, typical training habits and routines. We observed that both groups didn't have any specific exercises in weightlifting trainings to increase HGS values. One repetition maximum (1RM kg) results in snatch and clean-and-jerk in weightlifting events were obtained from the data of Turkish Weightlifting Federation, European Weightlifting Federation and World Weightlifting Federation. Demographic and anthropometric characteristics, training experiences (TE, days, years (yrs)), HGS and 1RM snatch and clean-andjerk data are shown in Table 1. The study, complied with the Declaration of Helsinki and the ethical approval was obtained from Studies Except Medicine and Medical Devices Ethics Committee in the University of Necmettin Erbakan, Meram Medical Faculty (dated 12/07/2019 and numbered 2014) for permission to conduct this study. All procedures followed in the study were in compliance with the ethics committee approval. The study criteria for the EWL groups were as follows: Athletes having participated in Olympic style weightlifting national training camps within the last two years and awarded a medal in international championships and trained six days a week during the same period were chosen. The study criteria for the sub-EWL groups were as follows: Athletes having done Olympic style weightlifting for at least the last two years, had a medal in national Olympic style weightlifting championships, participated in national weightlifting teams and trained for 4 days a week during the same period were chosen. Athletes with any joint problems of hand, wrist and elbow, history of fracture, musculoskeletal or neurological disorder, and deformities of upper extremity were excluded from the study.

\section{Measurements}

\section{Anthropometric measurements}

Prior to anthropometric measurements of the athletes in the study, each measurement test was experienced and potential problems were tried to be foreseen. Height (BH) was measured using a stadiometer (Seca 714, Hamburg, Germany) to the nearest $0.1 \mathrm{~cm}$ while maintaining maximal inspiration and body weight (BW) was measured by digital standing scale (BC-416 MA CIID Japan) to the nearest $0.1 \mathrm{~kg}$. The formula: body weight/(height) ${ }^{2}$ was used to calculate the BMI in $\mathrm{kg} / \mathrm{m}^{2}$. The methods and reference points used to obtain anthropometric measurements (right, left arm) of upper extremity of the participants were listed below. A measuring tape was used for the height and perimeter. For diameter measurement, a mechanic caliper was used (Holtain Bicondylar caliper).

Upper arm length (UAL): We measured the distance from acromion to olecranon. The measurement was done while the arm was near the body in rest position. [21]. Forearm length (FAL): The distance between olecranon to styloid process was measured while the elbow was at 90 degree-flexion [22]. Hand length (HL): The distance between end tip of middle finger to middle of distal line (plica carpalis distali), bordering hand and hand wrist was measured [23, 24]. Hand width (HW): The distance between proximal endings of the 2nd and 5th metacarpophalangeae joints was measured [22, 24]. Palm length (PL): It was determined through the measurement of the distance from the middle point of proximal line (plica digitopalmaris), which separates middle finger proximal from the palm, to the middle point of distal line (plica carpalis distalis), bordering hand and hand wrist [22-25]. Wrist diameters (WD): The measurements were taken by placing the caliper on the hand wrist on the length of styloid spines of radius and ulna and recording the reading on the caliper [26]. Elbow diameters (ED): While the elbow was at 90 degree-flexion, the distance between medial and lateral epicondyles of humerus [26]. Forearm circumference (FAC): While the elbow was at 90 degree-flexion and the forearm was at supination, the measurement was made from the $12 \mathrm{~cm}$ distal to olecranon without pressure [27]. Upper arm circumference (UAC): The criteria point was medial epicondyles of humerus. From this point, $10-15 \mathrm{~cm}$ or the most swollen area was marked and upper arm circumference was made while the arm was near the body in rest position [26]. To determine dominant (right) and non-dominant (left) hand, the athletes were asked to say which hand they use to write and prefer to carry out daily activities requiring hand force. All participants in our study were right-handed, that it, their right hand was dominant. No participants reported ambidexterity. Measurements were taken by a single researcher

Measurement of Handgrip Strength 
Prior to HGS measures, the athletes were given 3 minutes to warm up freely. For the dominant HGS (D-HGS) and non-dominant HGS (ND-HGS) measurement, standard adjustable-handle Jamar dynamometer (Asirnow Engineering Co, Los Angeles, CA, USA) was used. Obtained HGS values were recorded in $\mathrm{kg}$ values. We performed all measurements in a standardized arm position for HGS tests as suggested by the American Society of Hand Therapists [28]. The subject sat down while the shoulder was adducted and neutrally rotated, the elbow flexed at $90^{\circ}$ and the forearm and wrist were in neutral position. The subject was instructed to take two to three seconds to reach the maximum effort and then verbal encouragement was given consistently during measurements. For each strength test, the scores of three successive trials were recorded for each hand. The highest HGS value for each hand was used for analysis. The trials for each measurement were separated by a rest of at least one minute to minimize fatigue.

Statistical analysis

For the analysis of the data, SPPS 25 (IBM Corp. Released 2017. IBM SPSS Statistics for Windows, Version 25.0. Armonk, NY: IBM Corp.) statistical packaged software was used. Demographic variables, training experiences, weightlifting performances, D-HGS and ND-HGS values of elite and sub-elite athletes were studied to find out whether significant differences exist and t-Test analysis was carried out for independent groups. To compare anthropometric characteristics between elite and sub-elite groups, t-Test analysis was carried out for independent groups. To find out whether D-HGS and NDHGS values differ between the groups, t-Test analysis was conducted for dependent groups. The correlation between D-HGS and ND-HGS values and other variables were studied by using correlation analysis.

\section{Results}

Demographic and anthropometric characteristics, TE (days, years), 1RM snatch and clean-and-jerk, D-HGS and ND-HGS values of the study groups are shown in Table 1. We found that TE years, TE days, 1RM snatch and clean-and-jerk values of EWL in MWL and FWL groups were significantly higher than TE years, TE days, 1RM snatch and clean-and-jerk values of sub-EWL group. Also, D-HGS values of EWL in MWL group was significantly higher than D-HGS values of sub-EWL. No

Table 1. Demographic characteristics, weightlifting performances, D-HGS and ND-HGS for MWL and FWL groups (Mean \pm SD).

\begin{tabular}{|c|c|c|c|c|c|c|c|c|c|c|}
\hline \multirow{3}{*}{ Variable } & \multirow{2}{*}{\multicolumn{2}{|c|}{$\begin{array}{l}\text { MWL } \\
E W L \\
(n=25)\end{array}$}} & \multicolumn{7}{|c|}{ FWL } & \multirow{3}{*}{$\mathbf{t}$} \\
\hline & & & \multicolumn{2}{|c|}{$\begin{array}{l}\text { Sub-EWL } \\
(n=25)\end{array}$} & \multirow{2}{*}{$\mathbf{t}$} & \multicolumn{2}{|l|}{$\begin{array}{l}\text { EWL } \\
(n=20)\end{array}$} & \multicolumn{2}{|c|}{$\begin{array}{l}\text { Sub-EWL } \\
(n=20)\end{array}$} & \\
\hline & Mean & SD & Mean & SD & & Mean & SD & Mean & SD & \\
\hline $\begin{array}{l}\text { Age } \\
\text { (years) }\end{array}$ & 19.32 & 4.08 & 19.40 & 2.20 & -.09 & 19.00 & 2.87 & 18.50 & 1.15 & .72 \\
\hline $\begin{array}{l}\mathrm{BH} \\
(\mathrm{cm})\end{array}$ & 171.32 & 6.25 & 172.04 & 4.43 & -.47 & 161.75 & 8.48 & 160.00 & 5.40 & .78 \\
\hline $\begin{array}{l}\text { BW } \\
(\mathrm{kg})\end{array}$ & 79.04 & 20.60 & 79.12 & 10.15 & -.02 & 62.25 & 19.01 & 61.00 & 7.12 & .28 \\
\hline $\begin{array}{l}\text { BMI }(\mathrm{kg} / \\
\left.\mathrm{m}^{2}\right)\end{array}$ & 27.02 & 5.20 & 26.65 & 3.00 & .30 & 23.43 & 5.29 & 23.76 & 2.36 & -.25 \\
\hline $\begin{array}{l}\text { TE } \\
\text { (years) }\end{array}$ & 7.76 & 3.72 & 5.84 & 1.60 & $2.37 * *$ & 7.15 & 3.57 & 4.18 & 1.53 & $3.42 * *$ \\
\hline TE & & & & & & & & & & \\
\hline $\begin{array}{l}\text { (day/ } \\
\text { weekly) }\end{array}$ & 6.00 & .0 & 4.12 & .60 & $15.67 * * *$ & 6.00 & .0 & 4.05 & .60 & $14.42 * * *$ \\
\hline $\begin{array}{l}\text { 1RM } \\
\text { Snatch (kg) }\end{array}$ & 134.76 & 21.46 & 117.96 & 13.32 & $3.33 * *$ & 82.85 & 12.81 & 65.90 & 14.28 & $3.95^{* * *}$ \\
\hline $\begin{array}{l}\text { 1RM Clean } \\
\text { and jerk } \\
(\mathrm{kg})\end{array}$ & 164.56 & 26.26 & 144.72 & 17.01 & $3.17 * *$ & 104.45 & 17.52 & 82.40 & 18.79 & $3.84 * * *$ \\
\hline $\begin{array}{l}\text { D-HGS } \\
(\mathrm{kg})\end{array}$ & 59.16 & 15.35 & 51.92 & 8.25 & $2.08 *$ & 37.70 & 7.38 & 34.15 & 5.93 & 1.68 \\
\hline $\begin{array}{l}\text { ND-HGS } \\
(\mathrm{kg})\end{array}$ & 58.36 & 14.14 & 52.92 & 7.09 & 1.72 & 37.20 & 7.06 & 33.15 & 5.59 & 2.01 \\
\hline
\end{tabular}


statistically significant difference was observed in other variables of EWL and sub-EWL in MWL and FWL.

MWL: Male athletes in Olympic style weightlifting, FWL: Female athletes in Olympic style weightlifting, EWL: Elite Olympic style weightlifter, Sub-EWL: Sub-elite Olympic style weightlifter, BH: Body height, BW: Body weight, BMI: Body mass index, TE: Training experience. 1RM: 1 repetition maximum (best weightlifting performances), D-HGS: Dominant handgrip strength, ND-HGS: Non-dominant handgrip strength. SD: standard deviation. *Indicates $* \mathrm{p}<0.05, * * \mathrm{p}<0.01,{ }^{* * *} \mathrm{p}$ $<0.001$.

Some anthropometric characteristics of upper extremity of the study groups were shown in Table 2 . We didn't observe any statistically significant differences between anthropometric characteristics of upper extremity of EWL and sub-EWL in FWL group. No statistically significant difference existed among RWD, LWD, RED, LED, RFAC and LFAC measurements of EWL and subEWL in MWL group.

MWL: Male athletes in Olympic style weightlifting, FWL: Female athletes in Olympic style weightlifting, EWL: Elite Olympic style weightlifter, Sub-EWL: Subelite Olympic style weightlifter, RUAL, LUAL: (Right, Left upper arm length), RFAL, LFAL: (Right, Left forearm length), RHL, LHL: (Right, Left hand length), RHW, LHW: (Right, Left hand width), RPL, LPL: (Right, Left palm length), RWD, LWD: (Right, Left wrist diameters), RED, LED: (Right, Left elbow diameters), RFAC, LFAC: (Right, Left forearm circumference), RUAC, LUAC: (Right, Left upper arm circumference), 1RM: 1 repetition maximum (best weightlifting performances), D-HGS: Dominant handgrip strength, ND-HGS: Non-dominant handgrip strength, SD: standard deviation. *Indicates *p $<0.05, * * \mathrm{p}<0.01, * * * \mathrm{p}<0.001$.

Table 3 shows D-HGS and ND-HGS value comparison of EWL and sub-EWL in MWL and FWL groups. No statistically significant difference was found in D-HGS and ND-HGS values of EWL and sub-EWL in MWL and FWL groups.

MWL: Male athletes in Olympic style weightlifting, FWL: Female athletes in Olympic style weightlifting, EWL: Elite Olympic style weightlifter, Sub-EWL: Subelite Olympic style weightlifter, D-HGS: Dominant hand grip strength, ND-HGS: Non-dominant handgrip strength. SD: standard deviation. *Indicates *p $<0.05$, **p $<0.01, * * * \mathrm{p}<0.001$

The correlations between D-HGS and ND-HGS values of EWL and sub-EWL in MWL group and anthropometric characteristics, BMI, TE and weightlifting performances were shown in Table 4. It was observed that D-HGS and ND-HGS values of EWL were strong correlated. Moreover, a statistical correlation was found between D-HGS and ND-HGS values and other variables apart from age and

Table 2. Some anthropometric characteristics of upper extremity of Olympic style weightlifting athletes. (Mean \pm SD).

\begin{tabular}{|c|c|c|c|c|c|c|c|c|c|c|}
\hline \multirow{3}{*}{ Variable } & \multicolumn{4}{|l|}{ MWL } & \multirow{3}{*}{$\mathbf{t}$} & \multicolumn{4}{|l|}{ FWL } & \multirow{3}{*}{$t$} \\
\hline & \multicolumn{2}{|c|}{$\begin{array}{l}\text { EWL } \\
(n=25)\end{array}$} & \multicolumn{2}{|c|}{$\begin{array}{l}\text { Sub-EWL } \\
(n=25)\end{array}$} & & \multicolumn{2}{|c|}{$\begin{array}{l}\text { EWL } \\
(n=20)\end{array}$} & \multicolumn{2}{|c|}{$\begin{array}{l}\text { Sub-EWL } \\
(n=20)\end{array}$} & \\
\hline & Mean & SD & Mean & SD & & Mean & SD & Mean & SD & \\
\hline RUAL (cm) & 32.36 & 2.18 & 36.66 & 2.79 & $-6.08 * * *$ & 32.05 & 2.52 & 32.30 & 3.36 & -.27 \\
\hline LUAL (cm) & 32.28 & 2.23 & 36.30 & 2.74 & $-5.69 * * *$ & 32.00 & 2.55 & 32.15 & 3.36 & -.16 \\
\hline RFAL (cm) & 26.28 & 1.77 & 29.44 & 1.89 & $-6.10 * * *$ & 24.05 & 1.76 & 24.65 & 1.57 & -1.14 \\
\hline LFAL (cm) & 26.28 & 1.70 & 29.02 & 1.98 & $-5.24 * * *$ & 24.05 & 1.76 & 24.65 & 1.57 & -1.14 \\
\hline $\mathrm{RHL}(\mathrm{cm})$ & 18.20 & 1.22 & 19.18 & .89 & $-3.24 * *$ & 16.58 & .96 & 16.88 & 1.11 & -.91 \\
\hline LHL (cm) & 18.24 & 1.20 & 19.20 & .84 & $-3.28 * *$ & 16.59 & .94 & 16.83 & 1.08 & -.73 \\
\hline $\mathrm{RHW}(\mathrm{cm})$ & 8.92 & .72 & 10.32 & .89 & $-6.13 * * *$ & 7.70 & .52 & 7.85 & .75 & -.74 \\
\hline LHW (cm) & 8.90 & .72 & 10.18 & .86 & $-5.68 * * *$ & 7.70 & .50 & 7.85 & .75 & -.75 \\
\hline $\mathrm{RPL}(\mathrm{cm})$ & 10.10 & .61 & 11.06 & .74 & $-5.00 * * *$ & 8.80 & .55 & 9.15 & .59 & -1.95 \\
\hline LPL (cm) & 10.12 & .62 & 11.04 & .73 & $-4.79 * * *$ & 8.80 & .55 & 9.15 & .59 & -1.95 \\
\hline RWD (cm) & 5.84 & .33 & 5.90 & .29 & -.59 & 5.07 & .34 & 5.09 & .28 & -.15 \\
\hline LWD (cm) & 5.84 & .33 & 5.90 & .29 & -.59 & 5.07 & .34 & 5.09 & .28 & -.15 \\
\hline $\operatorname{RED}(\mathrm{cm})$ & 6.40 & .18 & 6.31 & .44 & .93 & 5.61 & .34 & 5.64 & .43 & -.28 \\
\hline LED (cm) & 6.40 & .18 & 6.31 & .44 & .93 & 5.61 & .34 & 5.64 & .43 & -.28 \\
\hline RFAC $(\mathrm{cm})$ & 29.06 & 2.74 & 28.44 & 2.34 & .86 & 24.20 & 2.65 & 23.50 & 1.18 & 1.08 \\
\hline LFAC (cm) & 29.06 & 2.82 & 28.30 & 2.35 & 1.04 & 24.25 & 2.65 & 23.60 & 1.13 & 1.01 \\
\hline RUAC (cm) & 31.62 & 3.76 & 34.28 & 3.61 & $-2.55^{*}$ & 27.40 & 3.76 & 27.35 & 2.70 & .05 \\
\hline LUAC $(\mathrm{cm})$ & 31.50 & 3.66 & 34.06 & 4.06 & $-2.34^{*}$ & 27.50 & 3.86 & 27.35 & 2.66 & .14 \\
\hline
\end{tabular}


Table 3. The comparison of D-HGS and ND-HGS values of Olympic style weightlifting athletes.

\begin{tabular}{|c|c|c|c|c|c|}
\hline Groups & & D-HGS, ND-HGS (kg) & Mean & SD & $\mathbf{t}$ \\
\hline \multirow{4}{*}{ MWL } & \multirow{2}{*}{$\operatorname{EWL}(n=25)$} & D-HGS & 59.16 & 15.35 & \multirow{2}{*}{.94} \\
\hline & & ND-HGS & 58.36 & 14.15 & \\
\hline & \multirow{2}{*}{ Sub-EWL $(n=25)$} & D-HGS & 51.92 & 8.25 & \multirow{2}{*}{-.72} \\
\hline & & ND-HGS & 52.92 & 7.09 & \\
\hline \multirow{4}{*}{ FWL } & \multirow{2}{*}{ EWL $(n=20)$} & D-HGS & 37.70 & 7.38 & \multirow{2}{*}{.58} \\
\hline & & ND-HGS & 37.20 & 7.06 & \\
\hline & \multirow[b]{2}{*}{ Sub-EWL $(n=20)$} & D-HGS & 34.15 & 5.93 & \multirow[b]{2}{*}{1.43} \\
\hline & & ND-HGS & 33.15 & 5.59 & \\
\hline
\end{tabular}

Table 4. The correlation between HGS values and other variables: anthropometric characteristics, TE, weightlifting performance of MWL.

\begin{tabular}{|c|c|c|c|c|}
\hline \multirow{3}{*}{ Variable } & \multicolumn{4}{|l|}{ MWL } \\
\hline & \multicolumn{2}{|l|}{$\begin{array}{l}\text { EWL } \\
(n=25)\end{array}$} & \multicolumn{2}{|c|}{$\begin{array}{l}\text { Sub-EWL } \\
(n=25)\end{array}$} \\
\hline & $\begin{array}{l}\text { D-HGS } \\
\text { (kg) }\end{array}$ & $\begin{array}{l}\text { ND-HGS } \\
\text { (kg) }\end{array}$ & $\begin{array}{l}\text { D-HGS } \\
\text { (kg) }\end{array}$ & $\begin{array}{l}\text { ND-HGS } \\
(\mathrm{kg})\end{array}$ \\
\hline D-HGS & 1 & $.962^{* * *}$ & 1 & $.599^{* *}$ \\
\hline ND-HGS & $.962^{* * *}$ & 1 & $.599^{* *}$ & 1 \\
\hline Age & .281 & .316 & .103 & -.009 \\
\hline $\mathrm{BH}(\mathrm{cm})$ & $.687^{* * *}$ & $.688^{* * *}$ & .227 & .094 \\
\hline BW (kg) & $.781^{* * *}$ & $.748^{* * *}$ & .266 & .058 \\
\hline $\mathrm{BMI}\left(\mathrm{kg} / \mathrm{m}^{2}\right)$ & $.709^{* * *}$ & $.678^{* * *}$ & .206 & .026 \\
\hline TE (years) & .325 & .389 & .113 & .194 \\
\hline 1RM Snatch (kg) & $.738^{* * *}$ & $.742^{* * *}$ & .347 & .313 \\
\hline 1RM Clean and jerk (kg) & $.721^{* * *}$ & $.727^{* * *}$ & .311 & .308 \\
\hline RUAL (cm) & $.615^{* *}$ & $.615^{* *}$ & .133 & .103 \\
\hline LUAL (cm) & $.585^{* *}$ & $.589^{* *}$ & .045 & .021 \\
\hline RFAL $(\mathrm{cm})$ & $.551^{* *}$ & $497^{*}$ & .149 & .114 \\
\hline $\operatorname{LFAL}(\mathrm{cm})$ & $.570^{* *}$ & $.520^{* *}$ & .209 & .033 \\
\hline $\mathrm{RHL}(\mathrm{cm})$ & $.734^{* * *}$ & $.720^{* *}$ & .150 & .178 \\
\hline $\mathrm{LHL}(\mathrm{cm})$ & $.722^{* * *}$ & $.711^{* *}$ & .201 & .048 \\
\hline $\operatorname{RHW}(\mathrm{cm})$ & $641^{* *}$ & $.681^{* * *}$ & .171 & .077 \\
\hline LHW $(\mathrm{cm})$ & $.650^{* * *}$ & $.693^{* * *}$ & .210 & .104 \\
\hline $\mathrm{RPL}(\mathrm{cm})$ & $.572^{* *}$ & $.568^{* *}$ & .339 & .255 \\
\hline LPL (cm) & $.636^{* *}$ & $.639^{* *}$ & .331 & .253 \\
\hline $\mathrm{RWD}(\mathrm{cm})$ & $.759^{* * *}$ & $.700^{* * *}$ & $.472^{*}$ & .322 \\
\hline LWD (cm) & $.759^{* * *}$ & $.700^{* * *}$ & $.472^{*}$ & .322 \\
\hline RED (cm) & $.622^{* *}$ & $.605^{* *}$ & .077 & -.013 \\
\hline LED (cm) & $.622^{* *}$ & $.605^{* *}$ & .077 & -.013 \\
\hline $\operatorname{RFAC}(\mathrm{cm})$ & $.751^{* * *}$ & $.714^{* * *}$ & .375 & .242 \\
\hline $\operatorname{LFAC}(\mathrm{cm})$ & $.752^{* * *}$ & $.710^{* * *}$ & .382 & .349 \\
\hline $\operatorname{RUAC}(\mathrm{cm})$ & $.694^{* * *}$ & $.650^{* * *}$ & .378 & .233 \\
\hline $\operatorname{LUAC}(\mathrm{cm})$ & $.683^{* * *}$ & $641^{* *}$ & $.428^{*}$ & .264 \\
\hline
\end{tabular}


TE values of EWL. We also found a correlation between D-HGS and ND-HGS values of sub-EWL. Moreover, it was determined RWD, LWD, LUAC measurements of sub-EWL and D-HGS values were correlated. It was observed that other variables didn't have any significant correlations with D-HGS and ND-HGS values.

MWL: Men athletes in Olympic style weightlifting, EWL: Elite Olympic style weightlifter, Sub-EWL: Subelite Olympic style weightlifter, BH: Body height, BW: Body weight, BMI: Body muscle index, TE: Training experience, 1RM: 1 repetition maximum (best weightlifting performances), RUAL, LUAL: (Right, Left upper arm length), RFAL, LFAL: (Right, Left forearm length), RHL, LHL: (Right, Left hand length), RHW, LHW: (Right, Left hand width), RPL, LPL: (Right, Left palm length), RWD, LWD: (Right, Left wrist diameters), RED, LED: (Right, Left elbow diameters), RFAC, LFAC: (Right, Left forearm circumference), RUAC, LUAC: (Right, Left upper arm circumference), D-HGS:
Dominant handgrip strength, ND-HGS: Non-dominant handgrip strength. ${ }^{*}$ Indicates $* \mathrm{p}<0.05, * * \mathrm{p}<0.01,{ }^{*} * \mathrm{p}$ $<0.001$.

Table 5 shows the correlations between D-HGS and ND-HGS values of EWL and sub-EWL in FWL group and other variables: anthropometric characteristics, BMI, TE, 1RM snatch and clean-and-jerk performance. We observed a statistically significant correlation between D-HGS and ND-HGS values of EWL in FWL group. Moreover, it was noticed that age, TE, RUAL, LUAL, RFAL, LFAL, RHW, LHW, RPL, LPL of EWL were not correlated with D-HGS and ND-HGS. Furthermore, it was observed that RHL, LHL, RWD, LWD, RED, LED were not correlated with ND-HGS. In addition, it was found that D-HGS and ND-HGS values of female subEWL were statistically correlated with 1RM snatch, 1RM clean-and-jerk, RUAL, LUAL, RPL and LPL.

FWL: Female athletes in Olympic style weightlifting, EWL: Elite Olympic style weightlifter, Sub-EWL:

Table 5. The correlations between HGS values of FWL and other variables: anthropometric characteristics, TE, 1RM snatch, 1RM clean-and-jerk performances.

\begin{tabular}{|c|c|c|c|c|}
\hline \multirow{3}{*}{ Variables } & \multicolumn{4}{|l|}{ FWL } \\
\hline & \multicolumn{2}{|l|}{$\begin{array}{l}\text { EWL } \\
(n=20)\end{array}$} & \multicolumn{2}{|c|}{$\begin{array}{l}\text { Sub-EWL } \\
(n=20)\end{array}$} \\
\hline & $\begin{array}{l}\text { D-HGS } \\
\text { (kg) }\end{array}$ & $\begin{array}{l}\text { ND-HGS } \\
\text { (kg) }\end{array}$ & $\begin{array}{l}\text { D-HGS } \\
(\mathrm{kg})\end{array}$ & $\begin{array}{l}\text { ND-HGS } \\
(\mathrm{kg})\end{array}$ \\
\hline D-HGS & 1 & $.860^{* *}$ & 1 & $.854^{* * *}$ \\
\hline ND-HGS & $.860^{* * *}$ & 1 & $.854^{* * *}$ & 1 \\
\hline Age & .164 & .229 & .159 & -.078 \\
\hline $\mathrm{BH}(\mathrm{cm})$ & $.751^{* * *}$ & $.638^{* * *}$ & .294 & .228 \\
\hline BW (kg) & $.760^{* * *}$ & $.575^{* *}$ & -.089 & -.223 \\
\hline $\mathrm{BMI}\left(\mathrm{kg} / \mathrm{m}^{2}\right)$ & $.623^{* *}$ & $.457^{*}$ & -.296 & -.402 \\
\hline TE (years) & -.022 & 118 & -.096 & -.154 \\
\hline 1RM Snatch (kg) & $.822^{* * *}$ & $.858^{* * *}$ & $.572^{* *}$ & $.623^{* *}$ \\
\hline 1RM Clean and jerk (kg) & $.747^{* * *}$ & $.785^{* * *}$ & $509^{*}$ & $.535^{*}$ \\
\hline $\operatorname{RUAL}(\mathrm{cm})$ & .284 & .404 & $.583^{* *}$ & $.474^{*}$ \\
\hline LUAL (cm) & .279 & .420 & $.583^{* *}$ & $.474^{*}$ \\
\hline $\operatorname{RFAL}(\mathrm{cm})$ & 301 & .156 & 206 & .022 \\
\hline LFAL (cm) & .301 & .156 & 206 & .022 \\
\hline $\mathrm{RHL}(\mathrm{cm})$ & $.455^{*}$ & .272 & .061 & -.070 \\
\hline LHL (cm) & $.473^{*}$ & .295 & .061 & -.070 \\
\hline RHW (cm) & .248 & .202 & .312 & .243 \\
\hline LHW (cm) & .304 & .303 & 323 & .326 \\
\hline $\mathrm{RPL}(\mathrm{cm})$ & .245 & .269 & $.583^{* *}$ & $.474^{*}$ \\
\hline LPL (cm) & .245 & .269 & $.583^{* *}$ & $.474^{*}$ \\
\hline RWD $(\mathrm{cm})$ & $.518^{*}$ & .333 & .206 & .022 \\
\hline LWD (cm) & $.518^{*}$ & .333 & .206 & .022 \\
\hline $\operatorname{RED}(\mathrm{cm})$ & $.459^{*}$ & .315 & .061 & -.070 \\
\hline $\operatorname{LED}(\mathrm{cm})$ & $.459 *$ & .315 & .061 & -.070 \\
\hline $\operatorname{RFAC}(\mathrm{cm})$ & $.747^{* * *}$ & $.538^{*}$ & .312 & .243 \\
\hline $\operatorname{LFAC}(\mathrm{cm})$ & $.752^{* * *}$ & $.545^{*}$ & .323 & .326 \\
\hline $\operatorname{RUAC}(\mathrm{cm})$ & $.670^{* * *}$ & $.512^{*}$ & -.214 & -.376 \\
\hline LUAC $(\mathrm{cm})$ & $.706^{* * *}$ & $.550^{*}$ & -.157 & -.322 \\
\hline
\end{tabular}


Subelite Olympic style weightlifter, BH: Body height, BW: Body weight, BMI: Body muscle index, TE: Training experience, 1RM: 1 repetition maximum (best weightlifting performances), RUAL, LUAL: (Right, Left upper arm lenght), RFAL, LFAL: (Right, Left forearm length), RHL, LHL: (Right, Left hand length), RHW, LHW: (Right, Left hand width), RPL, LPL: (Right, Left palm length), RWD, LWD: (Right, Left wrist diameters), RED, LED: (Right, Left elbow diameters), RFAC, LFAC: (Right, Left forearm circumference), RUAC, LUAC: (Right, Left upper arm circumference), D-HGS: Dominant handgrip strength, ND-HGS: Non-dominant handgrip strength. *Indicates $* \mathrm{p}<0.05, * * \mathrm{p}<0.01$, ${ }^{* * *} \mathrm{p}$ $<0.001$.

\section{Discussion}

No statistically significant difference was observed in age, BH, BW, and BMI of EWL and sub-EWL in MWL and FWL groups. Furthermore, although RUAL, LUAL, RFAL, LFAL, RHL, LHL, RHW, LHW, RPL, LPL, RUAC, LUAC values of upper extremity of sub-EWL in MWL group are higher than those of EWL, D-HGS of EWL was observed to be higher than D-HGS of subEWL. In addition, the findings of the study showed that no statistically significant difference existed between some anthropometric characteristics of upper extremity of EWL and sub-EWL in FWL, and D-HGS and ND-HGS values. In their study in which they tried to find out the correlation between performance feat and physical and physiological characteristics of top elite, elite and amateur male wrestlers, Demirkan et al. [17] stated that training experience and maximal oxygen intake levels of top elite and elite wrestlers were significantly higher than those of amateur wrestlers. However, the researchers also expressed that HGS of top elite, elite and amateur wrestlers were not statistically significant. In another study including male wrestlers aged 15-16-17 years, Demirkan [5] reported that HGS of 15-year-old wrestlers was much lower than right-left HGS of 16 and 17-yearold wrestlers. In a different study on wrestlers, N1kooie et al. [12] declared that HGS of both male senior and junior successful wrestlers was much higher than HGS of less successful wrestlers. In another study aiming to find out physiological variables of successful and less successful male wrestlers, Roemmich and Frappier [29] reported that right HGS of successful male wrestlers was $11.3 \%$ higher than less successful ones and left HGS of successful wrestlers was $13.3 \%$ higher than less successful ones. It was found in our study that some anthropometric characteristics of upper extremity of sub-EWL in MWL were higher than values of EWL, however, no statistically significant difference was observed in ND-HGS of groups. Besides, D-HGS of EWL was slightly higher than D-HGS of sub-EWL. Furthermore, although age, height and body weight values of male successful wrestlers in the study of Roemmich and Frappier [29] were lower than age, height and body weight values of male sub-EWL in our study, it was observed that right HGS of male successful wrestlers was higher than D-HGS of male sub-EWL. We suppose that the difference might be resulting from the fact that the training experience of male successful wrestlers (7.7 years) was longer than the training experience period of male sub-EWL (5.84 years). Drid et al. [18] reported that even though fitness and anthropometric characteristics of elite male judo athletes were highly higher than fitness level and anthropometric characteristics of sub-elite male judo athletes, no difference was observed in HGS values of elite and sub-elite judo athletes. In another study on elite judo athletes, it was reported that some anthropometric characteristics of upper extremity of elite judo athletes were higher than anthropometric feature of non-elite judo athletes, however, no statistically significant difference was observed in HGS values of elite and non-elite judo athletes [16]. Góngora et al. [11] explained that though the muscular area in the arm of male elite judo athletes was bigger than the muscular area in the arm of non-elite judo athletes, no statistically significant difference was observed in maximal isometric HGS values and maximal isometric HGS of female elite judo athletes were higher than maximal isometric HGS of non-elite female judo athletes. Nevertheless, the authors also reported that male and female elite judo athletes developed higher levels of relative isometric HGS in the maximum test and during all contractions of the endurance test than non-elite judo athletes. It was noticed that HGS values of elite and subelite male judo athletes in the study of Drid et al. [18] were higher than HGS values of EWL and sub-EWL in MWL group in our study. We are of the opinion that the reason for different HGS might be caused not only by differences in demographic characteristics, but also by the fact that upper extremity values of elite and sub-elite judo athletes (FAC and UAC) were bigger than those of male groups in our study. Furthermore, it was observed that HGS of athletes in FWL group was higher than HGS of female athletes in the study of Góngora et al. [11]. We think that different HGS values observed among female athlete groups might be due to the fact that the judo athletes in the study of Góngora et al. [11] were younger than female weightlifting athletes in our study. In a study examining characteristic features of elite male rock climbers, recreational climbers and non-climbers, it was reported that no difference was observed in anthropometric characteristics of the groups [30]. However, the authors reported that elite male climbers had a significantly higher average value than two other groups for HGS (left hand) and pinch strength (right and left hand). In another study on elite female climbers, recreational climbers and nonclimbers carried out by Grant et al. [31], they reported that elite female climbers had a significantly higher value for HGS than the recreational climbers, but not the nonclimbers. It was observed that HGS of elite male rock climbers in the study of Grant et al. [30] was higher than D-HGS and ND-HGS of male sub-EWL in our study. Also, it was determined that right HGS of elite female climbers in the study of Grant et al. [31] on female climbers was higher than D-HGS of female sub-EWL in our study. We estimate that HGS differences observed between weightlifters and climbers might be due to the 
fact that elite male and female rock climbers more dynamically use their hand and upper extremity in sport activities than weightlifting athletes. It was found that D-HGS and ND-HGS values of athletes attending international tennis tournaments were higher than HGS values of sedentary individuals [8]. In a study of physical and performance characteristics of U12, U14 and U16 ages national and regional (male, female) tennis players It was reported that HGS of U12 age male national groups and U12 and U16 age female national groups was higher than HGS values of regional tennis players within the same groups [32]. It was observed that UAC and FAC values of male tennis players included in the study of Gojanovic et al. [8] were smaller than UAC and FAC values of EWL and sub-EWL in MWL group in our study. Nonetheless, it was observed that D-HGS of male EWL along with D-HGS and ND-HGS of sub-EWL in our study was lower than reported HGS values of male tennis players. We consider that observed values of higher HGS values might be associated with bigger anthropometric characteristics of upper extremity as well as active use of forearm and upper arm in different types of sports. Moreover, it was worth considering that although the age group of U16 female national tennis players in the study of Ulbricht et al. [32] was smaller than the age group of sub-EWL in FWL in our study, they had higher HGS values. We surmise that these differences in observed HGS values might be because of differences in specific trainings unique to that type of sports. It was reported that motoric and some force parameters of regional representative female field hockey players were pretty higher than the parameters of local club female field hockey players [33]. However, the authors reported that no statistically significant difference existed in D-HGS values of regional representative and local club female field hockey players. Pion et al. [13] expressed that elite female volleyball players had higher motor coordination values than sub-elite volleyball players. However, they reported that HGS differences between elite and sub-elite female volleyball players were not statistically significant. Although EWL in FWL had higher weightlifting performance than sub-EWL in our study, no difference was observed in D-HGS and ND-HGS values of both groups. Moreover, it was found that D-HGS of regional female hockey players in the study of Keogh et al. [33] was found to be higher than D-HGS of female sub-EWL in our study and that HGS values of sub-elite female volleyball players included in the study of Pion et al. [13] were higher than HGS values of female sub-EWL in our study. It was to our surprise that although the age group of female volleyball players was low, their HGS values were almost similar to HGS values of female EWL and higher than HGS values of sub-EWL in our study. We think that HGS differences observed in female volleyball players and weightlifting athletes might be owing to the type of sport and different trainings pursued in these sports. In their study to figure out physical performance of elite, non-elite junior Olympic weightlifters, Fry et al. [34] explained and found that HGS of junior elite weightlifters was $52.5 \pm 8.1 \mathrm{~kg}$, whereas HGS of non-elite weightlifters was $48.1 \pm 13.6 \mathrm{~kg}$. Akkuş [15] reported that right HGS of elite level Turkish weightlifters was $55.90 \pm 10.93 \mathrm{~kg}$ and their left HGS was $50.89 \pm 9.54 \mathrm{~kg}$. Aydos et al. [19] studied HGS and relative parameters of athletes/players of team sports (basketball, football, volleyball) and individual sports (boxing, wrestling, judo, weightlifting) and they declared that right relative HGS was the highest in wrestlers and left relative HGS was the highest in weightlifting athletes. In their study, Sarıtaş et al. [20] examined some physical and physiological characteristics of male judo and weightlifting athletes and they reported that HGS of male weightlifting athletes (right hand $43.92 \pm 11.47 \mathrm{~kg}$, left hand $43.91 \pm 11.51 \mathrm{~kg}$ ) and HGS of judo athletes (right hand $46.47 \pm 11.31 \mathrm{~kg}$, left hand $46.98 \pm 10.12 \mathrm{~kg}$ ) were not statistically significant. D-HGS and ND-HGS values of male EWL in our study were observed to be higher than HGS values of elite athletes included in the studies of Fry et al. [34], Akkuş [15], Aydos et al. [19], Saritaş et al. [20]. We are of the opinion that the observed HGS value differences among weightlifting groups might be caused by demographic and anthropometric characteristics of the athletes. Besides this, from the viewpoint that weightlifting performance is positively correlated with HGS, we estimate that different HGS values among groups might be closely associated with weightlifting performance.

The differences between the dominant and nondominant extremity develop slowly and seem to depend on various factors, including the type of sport, specific trainings unique to that sport type, technical levels and training experience (years) of the athletes. Gojanovic et al. [8] found that in tennis, as an asymmetric type of sports, D-HGS values of athletes participated in national and international tournaments were higher than their ND-HGS values. The researchers stated that differences in D-HGS and ND-HGS values might be related to asymmetric trainings of tennis players as well as differences in muscular mass volume of upper extremity of these athletes. Gerodimos [35] reported that he found no statistically significant difference in dominant and non-dominant HGS values of prepubertal, adolescent and adult male basketball players (in all age groups). The author reported that the symmetry observed in dominant and non-dominant HGS parameters of the athletes might be caused by the fact that athletes constantly and evenly use both hands in basketball. In our study, no difference in D-HGS and ND-HGS values of EWL and sub-EWL in MWL group was observed. In a study aiming to find out anatomical asymmetry, functional asymmetry and dynamical asymmetry of female riders, it was reported that asymmetry was recorded in some parameters of higher level riders [36]. Moreover, the authors also reported that right HGS value was quite high in all female rider groups included in the study.

It was expressed that different D-HGS and ND-HGS values observed in female senior basketball player groups might be correlated with the conditioning (frequency, intensity, volume and mode of strength training) and 
years of practice of top level category athletes [10]. No asymmetric development was observed in D-HGS and ND-HGS values of EWL and sub-EWL in FWL group in our study. We consider that D-HGS and NDHGS symmetry in MWL and EWL groups is owing to the fact that weightlifting is a symmetric type of sports. Furthermore, it was observed that HGS values of adult male basketball players in the study of Gerodimos [35] were higher than HGS values of MWL group in our study and that HGS values of $\mathrm{U} 20$ and senior female basketball players included in the study of Pizzigalli et al. [10] were higher than HGS values of EWL and sub-EWL in FWL in our study. Specifically, it was surprising to find out that HGS values of U16 age group female basketball players were higher than HGS values of female EWL in our study. We think that these HGS differences between basketball players and weightlifting athletes might be related to the fact that basketball players use both hands more dynamically and intensively during in trainings and competitions than weightlifting athletes do.

HGS is affected by a number of factors and according to various research, HGS is known to be positively correlated with age, body weight, body height and BMI. Demirkan [5] studied male wrestlers and reported that right-left HGS of the athletes was positively correlated with age, height, body weight and BMI. Akkuş [15] divided elite male Olympic style weightlifting athletes into different weight classes and stated that right and left HGS values increase when body weight goes up. In a study that included elite female volleyball players, it was explained that HGS was positively correlated with height, BMI and age, in addition, tall players have higher HGS parameters [4]. It was reported that right and left HGS values of U14, 15, 16, 17, 18, 20 age and senior female basketball players were correlated with body height, body weight and BMI [10]. In our study, it was found D-HGS and ND-HGS values of EWL in MWL and FWL were correlated with BH, BW and BMI. However, D-HGS and ND-HGS of sub-EWL in MWL and EWL were not correlated with $\mathrm{BH}, \mathrm{BW}$ and $\mathrm{BMI}$.

HGS is a physiological variable that is affected by a number of factors including age, gender and body size, furthermore, strong correlations between handgrip strength and various anthropometric characteristics were reported. In their study, Pizzigalli et al. [10] declared that right and left HGS values of all basketball players from different age groups and with different sporting performance age had a statistical correlation with arm length and hand anthropometric measurements (hand span and hand transversal), however, they stated that HGS values and HL were not correlated. Furthermore, depending on the data of their study the same researchers also emphasized that along with body height measurement arm length measurement might be beneficial for the selection and ability assessment of female basketball players. Gojanovic et al. [8] reported that dominant, non-dominant UAC and non-dominant FAC of sedentary individuals was longer than UAC and FAC of tennis players, whereas right and left HGS values of the players were higher than HGS values of sedentary individuals. They also cited that dominant hand have higher UAC, FAC and HGS values and that the observed differences might be associated with the fact that tennis is an asymmetric sport. Góngora et al. [11] expressed that arm muscle area and FAC of judo athletes had a strong correlation with maximal isometric HGS. In a study looking into the correlations between HGS values and length, diameter and circumference of upper extremity of handball players, it was reported that right HGS of handball players have statistical correlations with UAC, FAC, WC and UAL [9]. In their study in which Koley et al. [7] studied the correlations between HGS and upper extremity characteristics of cricket players, they mentioned that right HGS values of cricket players were significantly and positively correlated with HL, HW and FAL. In our study, it was observed that D-HGS and NDHGS values of EWL in MWL had a positive correlation with anthropometric characteristics of upper extremity and that D-HGS of sub-EWL was correlated with RWD, LWD and LUAC. It was also found that D-HGS values of EWL in FWL had correlations with RHL, LHL, RWD, LWD, RED and LED and that D-HGS and ND-HGS values were correlated with RFAC, LFAC, RUAC and LUAC. Moreover, D-HGS and ND-HGS values of subEWL were correlated with RUAL, LUAL, RPL and LPL.

There are various studies showing that HGS values increase by training experience (TE) of athletes. Gerodimos [35] reported that HGS values of prepubertal (TE $1.99 \pm 1.39 \mathrm{yrs}$ ), adolescent (TE $3.52 \pm 1.67 \mathrm{yrs}$ ) and adult (TE $12.69 \pm 6.82 \mathrm{yrs}$ ) male basketball players increase by TE. In a study on female basketball players, it was found that depending on TE years, senior and U20 age athletes had higher HGS values than U14 and U15 age groups [10]. In another study on cricket players, although the researchers found a statistical difference between training experience of male adolescent (TE $4.3 \pm 0.4 \mathrm{yrs}$ ) and adult (TE 11,3 $\pm 4,5 \mathrm{yrs}$ ) cricket players, they reported that no significant difference was observed in right and left HGS values of the groups [6]. In our study, it was observed that D-HGS and ND-HGS values of EWL and sub-EWL in MWL and FWL were not correlated with TE. Moreover, in literature, it was mentioned that HGS positively increases depending on TE years. However, even though TE years of EWL in MWL and FWL were more than TE years of sub-EWL, it was to our surprise that no difference was observed in D-HGS and ND-HGS values of EWL and sub-EWL in FWL, and in ND-HGS values of EWL and sub-EWL in MWL group.

Turnagöl and Demirel [37] reported that for Turkish national weightlifting athletes, the diameter of femur epicondyle is correlated with clean and jerk movement and the circumference of biceps is correlated with cleanand-jerk movement and total weight lifted. Fry et al. [34] reported that a correlation was present in weightlifting performance of junior weightlifting athletes and HGS values. Akkuş [15] declared that HGS (especially right HGS) is one of the most important characteristics to forecast snatch and clean-and-jerk performance of elite Turkish weightlifting athletes. The same author also 
stated that a positive correlation exists in weightlifting performance (snatch and clean-and-jerk) and WD, UAL and FAL. Erdağı et al [38] reported that Olympic style weightlifting training positively increased the finger strength of female weightlifting athletes. Hoffman et al. [14] reported that baseball-specific performance variables were significantly correlated with HGS and lean body mass, speed, lower-body power. In our study, it was observed that D-HGS and ND-HGS values of EWL in MWL and FWL groups were correlated with 1RM snatch and 1RM clean-and-jerk performances. However, no correlation was present in weightlifting performance and D-HGS and ND-HGS values of sub-EWL in MWL and FWL groups.

Some limitations were present in our study. The main limitation was the insufficient number of elite Olympic weightlifting athletes (international medalists). In particular, we had only a limited number of elite female athletes in Turkey. Another limitation was that because EWL (males and females) spent most of the year in national weightlifting training camps, these athletes had more intensive trainings and higher nutrition levels than sub-EWL (males and females).

The assessments made on some anthropometric characteristics of upper extremity and HGS values of MWL and FWL in our study are not only beneficial for determining differences among EWL and sub-EWL Olympic style weightlifting athletes, the findings of these evaluations are also beneficial for weightlifting trainers and athletes that take charge in regional and national teams. Moreover, in light of study findings, although both training experience (years/days) and weightlifting performance (snatch and clean-and-jerk) values of EWL in MWL and FWL groups were higher than the values of
sub-EWL, it was thought-provoking to find out that NDHGS values of EWL in MWL group and both D-HGS and ND-HGS values of EWL in FWL group were almost at the same level with HGS values of sub-EWL.

\section{Conclusions}

Considering these facts, we had the conclusion that exercises to develop handgrip strength of elite weightlifting athletes do not exist or are not practiced or Olympic style weightlifting trainings or exercises practiced in these trainings are not highly effective in the development of handgrip strength of these athletes. Consequently, we are of the opinion that adding specific exercises into trainings to develop handgrip strength of male and female Olympic style weightlifting athletes might contribute to athletic achievements of these athletes.

\section{Acknowledgments}

I would like to thank the female and male Olympic style weightlifting athletes along with trainers who participated in this research.

\section{Presented}

The paper presented orally at the IV. International Scientific and Vocational Studies Congresss- Science and Health 7-9 November 2019, Ankara, Turkey.

\section{Funding}

This project was self-funded.

\section{Conflict of interest}

There are no conflicts of interest.

\section{References}

1. Shea J. The importance of grip strength. Journal of Strength and Conditioning Research, 2007; 21(3): 923- 929. https://doi.org/10.1519/00124278-200708000-00045

2. Nazmi N, Abdul Rahman M, Yamamoto S, Ahmad $\mathrm{S}$, Zamzuri H, Mazlan SA. Review of classification techniques of emg signals during 1sotonic and isometric contractions. Sensors, 2016; 16(8): 1304. https://doi.org/10.3390/s16081304

3. Gambetta V. Round Table. New studies in athletics Rev, 1988; 3: 27 .

4. Faraji E, Sarvari F, Atri AE. Predicting grip strength based on anthropometric characteristics in female junior volleyball players. Iranian journal of health and physical activity, 2014; 5(1): 25-28.

5. Demirkan E. Age-related patterns of physical and physiological characteristics in adolescent wrestlers. Monten. J. Sports Sci. Med, 2015 (b); 4 (1): 13-18.

6. Singla D, Hussain ME. Association between handgrip strength and back strength in adolescent and adult cricket players. International Journal of Adolescent Medicine and Health, 2018; https://doi.org/10.1515/ijamh-2017-0177

7. Koley S, Yadav M, Sandhu J. Estimation of hand grip strength and its association withsome anthropometric traits in cricketers of Amritsar, Punjab, India. The internet journal of biological anthropology, 2009; 3(1): 7. https://doi.org/10.5580/18de

8. Gojanovic B, Waeber B, Gremion G, Liaudet L, Feihl F. Bilateral symmetry of radial pulse in high-level tennis players: implications for the validity of central aortic pulse wave analysis. Journal of Hypertension, 2009; 27(8): 1617-1623 https://doi.org/10.1097/HJH.0b013e32832bffc0

9. Yıldırım İ, Baş O, Kabadayı M, Taşmektepligil MY, Ocak Y, Karagöz Ş. Examination of the correlation of hand grip strength with upper extremity physical charactercistics in the male players of handball super league. Mustafa Kemal university journal of physical education and sport sciences, 2010; 1(1): 9-15.

10.Pizzigalli L, Cremasco MM, Torre A, Rainoldi A, Benis R. Hand grip strength and anthropometric characteristics in Italian female national basketball teams. The Journal of Sports Medicine and Physical Fitness, 2017; 57(5): 521-528. https://doi.org/10.23736/S00224707.16.06272-1

11.Góngora JB, Almei F, Padial P, Domínguez JB, Feriche $\mathrm{B}$, Feriche B. Maximal isometric handgrip strength and endurance differences between elite and non- elite young judo athletes. Archives of Budo|Science of Martıal Arts, 2013; 9(4): 239.

12.N1kooie R, Cheraghi M, Mohamadipour F. Physiological determinants of wrestling success in elite Iranian senior and junior Greco-Roman wrestlers. The Journal of Sports 
Medicine and Physical Fitness, 2015; 57(3): 219-26. https://doi.org/10.23736/S00224707.16.06017-5

13.Pion JA, Fransen J, Deprez DN, Segers VI, Vaeyens R, Philippaerts RM, Lenoir M. Stature and jumping height are required in female volleyball, but motor coordination is a key factor for future elite success. Journal of Strength and Conditioning Research, 2015; 29(6): 1480-1485. https://doi.org/10.1519/JSC.0000000000000778

14.Hoffman JR, Vazquez J, Pichardo N, Tenenbaum G. Anthropometric and performance comparisons in professional baseball players. Journal of Strength and Conditioning Research, 2009; 23(8): 2173-2178. https://doi.org/10.1519/JSC.0b013e3181bcd5fe

15.Akkuş $H$. The relationships between anthropometric characteristics, biomotor abilities, physiological characteristics and success in elite weightlifters. Doctoral Dissertation in Physical Education and Sports, 1994.

16.Franchini E, Takito1 MY, Kiss MAPDM, Sterkowicz S. Physical fitness and anthropometrical differences between elite and non-elite judo players. Biology of Sport, 2005; 22(4): 315-318.

17.Demirkan E, Koz M, Kutlu M, Favre M. Comparison of Physical and Physiological Profiles in Elite and Amateur Young Wrestlers. Journal of Strength and Conditioning Research, 2015;29:1876-83. https://doi.org/10.1519/JSC.0000000000000833

18.Drid P, Casals C, Mekic A, Radjo I, Stojanovic M, Ostojic SM. Fitness and anthropometric profiles of internationalvs.national judo medalists in half-heavyweight category. Journal of Strength and Conditioning Research, 2015; 29(8): 2115-2121. https://doi.org/10.1519/JSC.0000000000000861

19. Aydos L, Pepe H, Karakus H. The research of relative force evaluations in some team and individual sports. Gazi Üniversitesi Kırşehir Eğitim Fakültesi, 2004; 5(2): 307- 314.

20.Sarıtaş N, Hayta Ü, Kaya M. Examination of some physical and physiological findings of male judoka and weightlifters in individual sports. Gaziantep Üniversitesi Spor Bilimleri Dergisi, 2018; 3(4): 200-211.

21.Zorba E, Ziyagil MA. Body composition and measurement methods. Gen Matbaacllk, 1995; 44-68: 227-235. (in Türkish).

22.Nicolay CW, Walker AL. Grip strength and endurance: influences of anthropometric variation, hand dominance, and gender. Inter $J$ Ind Ergon, 2005; 35: 605-618. https://doi.org/10.1016/j.ergon.2005.01.007

23.Fallahi A, Jadidian A. The effect of hand dimensions, hand shape and some anthropometric characteristics on handgrip strength in male grip athletes and non athletes. Journal of Human Kinetics, 2011; 29(1): 151-159. https://doi.org/10.2478/v10078-011-0049-2

24.Pheasant S. Anthropometry, Ergonomics and the Design of Work. 2nd ed. London: Taylor and Francis; 1996.

25.Clerke AM, Clerke JP, Adams RD. Effects of hand shape on maximal isometric grip strength and its reliability in teenagers. Journal of Hand Therapy, 2005; 18(1): 19-29. https://doi.org/10.1197/j.jht.2004.10.007
26.Otman SA, Demirel H, Sade A. Basic Evaluation Principles in Treatment Movements. Ankara: Hacettepe University Physical Therapy and Rehabilitation Publications; 1998. (in Türkish).

27.Anakwe RE, Huntley JS, Mceachan JE. Grip strength and forearm circumference in a healthy population. Journal of Hand Surgery (European Volume), 2007; 32(2): 203- 209. https://doi.org/10.1016/J.JHSB.2006.11.003

28.28. Fess EE. Grip Strength. In: J.S. Casanova (ed.), Clinical assessment recommendations. Chicago: American Society of Hand Therapists; 1992. P. 41-45.

29.Roemmich JN, Frappier JP. Physiological Determinants of Wrestling Success in High School Athletes. Pediatric Exercise Science, 1993; 5(2), 134-144. https://doi.org/10.1123/pes.5.2.134

30.Grant S, Hynes V, Whittaker A, Aitchison T. Anthropometric, strength, endurance and flexibility characteristics of elite and recreational climbers. Journal of Sports Sciences, 1996; 14(4): 301-309. https://doi.org/10.1080/02640419608727715

31.Grant S, Hasler T, Davies C, Aitchison TC, Wilson J, Whittaker A. A comparison of the anthropometric, strength, endurance and flexibility characteristics of female elite and recreational climbers and non-climbers. Journal of Sports Sciences, 2001; 19(7): 499- 505. https://doi.org/10.1080/026404101750238953

32.Ulbricht A, Fernandez-Fernandez J, Mendez-Villanueva A, Ferrauti A. Impact of fitness characteristics on tennis performance in elite junior tennis players. Journal of Strength and Conditioning Research, 2016; 30(4): 989-998. https://doi.org/10.1519/JSC.0000000000001267

33.Keogh JWL, Weber CL, Dalton CT. Evaluation of anthropometric, physiological, and skill-related tests for talent identification in female field hockey. Canadian Journal of Applied Physiology, 2003; 28(3): 397-409. https://doi.org/10.1139/h03-029

34.Fry AC, Ciroslan D, Fry MD, Leroux CD, Schillıng BK, Chıu LZ.Anthropometric and performance variables discriminating elite American junior men weightlifters. Journal of Strength and Conditioning Research, 2006; 20(4): 861-866. https://doi.org/10.1519/00124278-200611000-00023

35. Gerodimos V. Reliability of handgrip strength test in basketball players. Journal of Human Kinetics, 2012; 31(1): 25-36. https://doi.org/10.2478/v10078-012-0003-y

36.Hobbs SJ, Baxter J, Broom L, Rossell LA, Sinclair J, Clayton HM. Posture, flexibility and grip strength in horse riders. Journal of Human Kinetics, 2014; 42(1):113-125. https://doi.org/10.2478/hukin-2014-0066

37. Turnagöl HH, Demirel H. Somatotype profile and relationship of some anthropometric variables with performance of Turkish national weightlifters. Journal of Sport Sciences, 1992; 3(3): 11-18.

38.Erdağı K, Yargıç MP, Kürklü GP, Aydın L. Accuracy of pinch force sense in elite female adolescent weightlifters. Turkish Journal of Sports Medicine, 2019; 55: 1-7. https://doi.org/10.5152/tjsm.2020.165 


\section{Information about the author:}

Kenan Erdağı; Assistant Professor; http://orcid.org/0000-0002-2338-6546; kenanerdal@hotmail.com; Faculty of Education, Necmettin Erbakan University; Konya, 42090, Turkey.

\section{Cite this article as:}

Kenan Erdağı. The study of the correlations between handgrip strength and some anthropometric characteristics of upper extremity of elite and sub-elite olympic style weightlifting athletes. Physical education of students, 2020;24(1):19-30.

https://doi.org/10.15561/20755279.2020.0103

This is an Open Access article distributed under the terms of the Creative Commons Attribution License, which permits unrestricted use, distribution, and reproduction in any medium, provided the original work is properly cited http://creativecommons.org/licenses/by/4.0/deed.en

Received: 26.10 .2019

Accepted: 23.11.2019; Published: 04.02.2020 